\title{
Skin Partial Response GvHD
}

National Cancer Institute

\section{Source}

National Cancer Institute. Skin Partial Response GVHD. NCI Thesaurus. Code C126714.

An NIH skin score that has decreased by 1 or more points. 